\title{
Echinops phaeocephalus (Asteraceae) Türünün Antimikrobiyal ve Antioksidan Aktivitesi
}

\author{
Handan ŞAPCI ${ }^{1}$, Cem VURAL ${ }^{2}$ \\ ${ }^{1}$ Çukurova Üniversitesi, Aladağ Meslek Yüksekokulu, Ormancılık Bölümü, ADANA \\ ${ }^{2}$ Erciyes Üniversitesi, Fen Fakültesi, Biyoloji Bölümü, KAYSERİ \\ $\varangle$ : hsapci@cu.edu.tr
}

Geliş (Received): 27.01.2016

Kabul (Accepted): 21.02.2017

\begin{abstract}
ÖZET: Bu çalışmada, E. phaeocephalus türünün antimikrobiyal ve antioksidan aktivitesini araştırmak amaçlanmıştır. E. phaeocephalus türünün ekstraksiyonları hekzan, methanol ve kloroform olmak üzere üç farklı çözücü kullanılarak elde edilmiştir. Antioksidan kapasitesi DPPH radikali süpürücü aktivite tayini, toplam fenolik içeriğin belirlenmesi ve toplam flavanoid içeriğinin belirlenmesi testleri yapılarak belirlenmiştir. Antimikrobiyal aktiviteleri disk difüzyon testi ve mikrodilüsyon (MIC) yöntemi kullanılarak araştırılmıştır. Çözücüler ekstraksiyon verimi bakımından değerlendirildiğinde metanolün diğer çözücülerden daha etkili olduğu tespit edilmiştir. Echinops phaeocephalus türü ekstraktlarının mikroorganizmalar üzerinde değişen etkilere sahip olduğu gözlenmiştir. Antioksidan aktivite tayini testleri neticesinde, fenolik madde miktarı en yüksek hekzan ile elde edilen ekstraktda gözlenirken, flavanoid madde içeriği bakımından zengin olan ekstrakt metanol ile elde edilen ekstrakt olmuştur. DPPH radikali süpürücü aktivite tayini sonuçlarında ise özellikle metanol ve hekzan ekstraktlarından yüksek verim elde edilmiştir. Elde edilen sonuçlar neticesinde de E. phaeocephalus türünün önemli derecede antioksidan ve antimikrobiyal aktiviteye sahip olduğu belirlenmiştir.
\end{abstract}

Anahtar Kelimeler: Compositae, fenolik içerik, flavanoid, antibakterial, antifungal

\section{Antimicrobial and Antioxidant Activity of Echinops phaeocephalus (Asteraceae)}

\begin{abstract}
The aim of this study was to investigate antimicrobial and antioxidant activity of Echinops phaeocephalus extracts prepared with different solvents. For antioxidant potential evaluation, extraction of $E$. phaeocephalus was obtained by three solvents of different polarities including hexane, methanol and chloroform. Antioxidant potential was evaluated by estimating DPPH radical scavenging activity, total phenolic activity and total flavonoid activity assay. Antimicrobial activity was determined by minimal inhibitory concentration (MIC) and disc diffusion tests. Efficiency of different solvents was compared for the yield of antioxidant extracts from samples. The study results indicated that, E. phaeocephalus could be an important natural antioxidant. The evaluations of solvents for effect of extraction resulted that methanol was more effective than other solvents. Echinops phaeocephalus derived extracts were observed to have varies effects on microorganisms. The results of the antioxidant activity assay indicated that the highest phenolic content was in the extract of hexane, while the highest flavonoid content was in methanol extract. Especially methanol and hexane extracts showed high efficiency according to DPPH radical scavenging activity results. Our results concluded that E. phaeocephalus sustains an important antioxidant and antimicrobial activity.
\end{abstract}

Keywords: Compositae, phenolic content, flavonoid, antibacterial, antifungal

\section{GÍRIŞ}

Bitkiler yapısında bulunan farmakolojik özelliklere sahip bileşikler ve biyoaktif maddeler sayesinde günümüzde kullanılan ilaçların birçoğunun kökenini oluşturmaktadır (Haslam, 1996; Nissen ve Evans, 2012). $\mathrm{Bu}$ sebeple, günümüzde bitkilerden elde edilen ekstraktların ana etken maddelerinin elde edilip değerlendirilmesi ekonomik açıdan büyük önem taşımaktadır. Biyoçeşitlilik açısından bir kıta zenginliği ve özellikleri taşıdığı için Küçük Asya ismini de alan Anadolu'da 3035'i endemik olmak üzere; 9753 bitki türü doğal olarak yayılış göstermektedir (Güner ve ark. 2012). $\mathrm{Bu}$ türler arasında pek çok tıbbi bitki de yer almaktadır. Bitkilerin ürettiği ikincil metabolitler bitkilerdeki biyoaktif maddelerin ana kaynağını oluşturur. Echinops L. (Asteraceae) cinsi dünya üzerinde olduğu gibi ülkemizde de geniş bir yayılışa sahip olup dünya üzerinde bilinen tür sayısı 125 ile 130 arasında değişmektedir. Yaygın olarak, tropik Afrika'nın yarı nemli alanları, Kuzey Afrika'nın yarı kurak alanları,
Akdeniz havzası ve Orta Asya'ya kadar Avrasya'nın ılıman kuşağında yayılış gösteren, Echinops cinsinin ülkemizde son çalışmalara göre 28 taksonu yayılış göstermektedir. Echinops cinsine ait çeşitli taksonlar üzerinde yapılan bazı araștırmalarda, bu türlerden elde edilen çeşitli ekstraktların belirgin bir biyolojik aktiviteye sahip olduğu gözlemlenmiştir. Örneğin, Hymete ve ark., (2005), Echinops longisetus türünün yaprak ve gövde ekstraksiyonlarında bulunan flavinoid bileşenlerinin gram-negatif organizmalara karşı güçlü inhibitör etkiye sahip olduğunu belirtmişlerdir. Toroğlu ve ark. (2012), E. microcephalus ve E. viscosus subsp. bithynicus taksonlarının antimikrobiyal etkilerini araştırmışlar ve bu taksonların çeşitli ilaç tedavilerinde mikroorganizmalara karşı kullanılabilecek antimikrobiyal etkiye sahip olduğu sonucuna ulaşmışlardır. Ameya ve ark. (2016) E. kebericho türünün bazı insana patojen olduğu bilinen bakteri ve mantarlar üzerindeki antimikrobiyal etkisi test etmişler ve $E$. kebericho türünün insanlar üzerinde bulaşıcı etkisi 
olan ve olmayan çeşitli hastalıkların tedavisinde kullanılabileceğini belirtmişlerdir. $\mathrm{Bu}$ çalışmada kapsamında ise, Bitlis-Şırnak yöresine endemik olan $E$. phaeocephalus türünün antimikrobiyal ve antioksidan etkileri incelenmiştir. Antimikrobiyal aktiviteleri disk difüzyon testi ve mikrodilüsyon yöntemi kullanılarak belirlenmiştir. E. phaeocephalus'un antioksidan kapasitesi ise toplam fenolik içeriğin belirlenmesi, toplam flavanoid içeriğinin belirlenmesi, hidroksil radikal savıcı etkinin belirlenmesi ve DPPH radikali süpürücü aktivite tayini testleri yapılarak belirlenmiştir.

\section{MATERYAL ve METOT}

$\mathrm{Bu}$ çalışmada Bitlis-Şırnak yöresine endemik olan Echinops phaeocephalus kullanılmıştır. Toplanan bitki örnekleri kurutulup, parçalayıcı yardımı ile toz hale getirilmiş ve bu örneklerden 10 gr tartılarak $250 \mathrm{~mL}$ solvent (metanol, kloroform veya hekzan) içinde çözülmüştür. 10 saat boyunca Soxhlet cihazı yardımı ile ekstraksiyonu yapılan örnekler daha sonra liyofilize edilmiştir. DMSO içinde maksimum çözünen miktarlarının belirlenmesinin ardından E. phaeocephalus türünün antimikrobiyal aktiviteleri patojen gram pozitif ve gram negatif bakterilere ve mayaya karşı, National Comitee for Clinical Laboratory Standards tarafindan önerilen yönteme göre, disk difüzyon testi ve mikrodilüsyon yöntemi (MIC) kullanılarak in vitro olarak gözlemlenmiştir (NCCLS, 1997; 1999). Çözünmüş örnekler $0.22 \mu \mathrm{m}$ steril filtreden geçirilerek stoklar haline hazırlanmıştır. Steril stoklardan $6 \mathrm{~mm}$ çapındaki kağıt disklere (Antimicrobial Sussptibility TEST DISCS, Oxoid) emdirilmiştir. Negatif kontrol olarak DMSO kullanılmıştır. Pozitif kontrol olarak ise bakteriler için Ampisilin ve Trimethoprim, mayalar için ise Nystatin ve Tetracycline aktif maddeleri kullanılmıştır. NCCLS (1997), tarafından önerilen yönteme göre, $100 \mu \mathrm{L}$ x $10^{8} \mathrm{cfu} / \mathrm{mL}$ (Mc Farland bulanıklık standard1 0.5) eş değer hücre MHA üzerine steril eküvyon çubuğu ile eşit miktarda ekilmiştir. Ardından diskler yerleştirilerek, $37^{\circ} \mathrm{C}$ 'de $24-48$ saat inkübe edilmiş ve antimikrobiyal aktivite diskler etrafında oluşan zon çapları kumpas yardımıyla ölçülerek belirlenmiștir. E. phaeocephalus türünün Minimum İnhibisyon Konsantrasyonu (Minimal Inhibition Concentration, MIC) mikro dilüsyon yöntemi ile çalışılmıştır (NCCLS, 1999). DMSO içeriğinde hazırlanan ve filtre edilen ana stoktan MHB ya ad YPDB içerisinde $1000 \mu \mathrm{g} / \mathrm{ml}$ çalışma ara stoku oluşturulmuştur. Ara stoktan sıvı besi yerine olmak üzere, sürekli yarıya düşürülerek $10 \mathrm{ml}$ sıvı besi yeri içeren steril tüplerde her bir değer için bağımsız olarak çalışma stokları hazırlanmıştır. MIC okumalarında, 96'lık (microplate) ELISA kapları kullanılmıştır. Microplate 300 rpm'de 30 saniye rotary inkübator ile çalkalanarak $37{ }^{\circ} \mathrm{C}$ 'de 24-48 saat inkübe edilmiştir. Bakteriyel büyüme kuyucukların dibindeki beyaz pelletlerin varlığ 1 incelenerek belirtilmiştir.

Bitkiye ait toplam fenolik içerik Folin-Ciocalteu metoduna göre belirlenmiştir. Standart oluşturmada gallik asit kullanılmıştır (Gamez-Meza ve ark., 1999).
$0.5 \mathrm{ml}$ Folin-Ciocalteu ve $1.5 \mathrm{ml} \mathrm{Na} 2 \mathrm{CO} 3$ (\%20)'den oluşan reaksiyon ortamına son konsantrasyon 0.06 $\mathrm{mg} / \mathrm{ml}$ olacak şekilde elde edilen bitki özütü ilave edilmiş ve son hacim $10 \mathrm{ml}$ 'ye tamamlanarak oda sicaklığında ve karanlık ortamda iki saat inkübasyondan sonra 760 nm'de absorbans değerleri belirlenmiştir. Standart kalibrasyon eğrisi olarak gallik asit kullanılmış ve test bileşiklerin bir gramına karşılık gelen gallik asit miktarı gallik asit standart grafiği kullanılarak belirlenmiştir. 1-1 difenil 2 pikril hidrazil (DPPH) radikalinin \%50 'sinin bitki ekstraktı tarafindan süpürülmesi esasına göre belirlenmiştir. $\quad 200 \mu \mathrm{L} / \mathrm{mL}$ konsantrasyonlarda hazırlanan standart çözeltilerden 1'er mL alınarak, $4 \mathrm{~mL}$ $0.1 \mathrm{mM}$ DPPH (etanolde) çözeltisi ilave edilerek, karanlıkta ve oda sıcaklığında 30 dakika bekletilmiştir. Ardından spektrofotometrede $517 \mathrm{~nm}$ absorbans değerleri belirlenmiştir. Karanlık ortamda, oda sıcaklığında 40 dakika inkübe edildikten sonra 417 nm'de absorbans değerleri belirlenmiştir. Standart antioksidan madde olarak bütillenmiș hidroksi toluen (BHT) kullanılmıştır. Standart antioksidanlar ile bitkiye ait DPPH aktiviteleri karşılaştırılmıştır (Gezer ve ark. 2006).

Toplam flavonoid içeriğin belirlenmesinde Chang ve ark. tarafından belirtilen yöntem kullanılmıştır (Chang ve ark., 2002). Bitki özütleri $10 \mathrm{mg} / \mathrm{ml}$ konsantrasyon da DMSO içinde çözülerek ana stok oluşturulmuştur. Ardından Standart olarak bilinen bir flavonid olarak kuersetin kullanılmıştır. Standart flavonoid grafiğininden faydalanarak bitki ekstrelerinde bulunan flavonoid içerik belirlenmiştir. \% 10'luk alüminyum nitrattan $100 \mu 1,1 \mathrm{M}$ potasyum asetattan $100 \mu$ l alınıp bitki özütü son konsantrasyonu $100 \mu \mathrm{g} / \mathrm{ml}$ olacak şekilde bitki özütü ilave edilerek son hacim \% 80'lik etanol ile 5 ml'ye tamamlanmıştır.

Çalışılan tüm antimikrobiyal ve antioksidan çalışmalarından elde edilen verilere SPSS istatistik analiz programı kullanılarak standart hatalar belirlenmiştir. Denemeler üç tekrarlı olarak gerçekleştirilmiştir.

\section{Test Mikroorganizmalart}

Antimikrobiyal çalışmalarda kullanılan test mikrrorganizmaları 14 bakteri ve bir mantar suşundan oluşmaktadır; Staphylococcus aureus ATCC 25923 (gram-possitive), Enterococcus faecalis ATCC 29212 (gram-possitive), Pseudomonas fluorescens ATCC 49838 (gram-negative), Staphylococcus epidermidis ATCC 12228 (gram-possitive), Micrococcus luteus ATCC 10240 (gram-possitive), Listeria monocytogenes ATCC 19115 (gram-possitive), Bacillus cereus ATCC 11778 (gram-possitive), Klebsiella pneumonia ATCC 13883 (gram-negative), Enterobacter aerogenes ATCC 13048 (gram-negative), Escherichia coli ATCC 25922 (gram-negative), Bacillus subtilis ATCC 6633 (grampossitive), Proteus mirabilis ATCC 25933 (gramnegative), Pseudomonas aeruginosa ATCC 27853 (gram-negative), Corynebacterium renale ATCC 19412 (gram-possitive), Candida albicans ATCC 90028. 


\section{BULGULAR ve TARTIŞMA}

Ekstraksiyon Verimi

Bitki ekstraksiyonu üç farklı çözücü kullanılarak elde edilmiş olup, en verimli kuru madde eldesine methanol ekstraktından sağlanmıştır.

\section{Antimikrobiyal Aktivite Sonuçları}

Farklı çözücülerin bitkiye ait farklı molekülleri çözdüğü ve bunun sonucunda mikroorganizmalar üzerinde değişen etkiler meydana getirdiği belirlenmiştir. Echinops phaeocephalus türünün çeşitli çözücüler yardımı ile elde edilen ekstraksiyonlarının disk difüzyon test değerleri Çizelge 1'de verilmiştir. Disk difüzyon test sonuçlarına göre methanol ekstraktlarının K. Peumoniae, $C$. renale ve $M$. luteus mikroorganizmaları üzerinde, kloroform ekstraktlarının $B$. cereus ve $C$. renale mikroorganizmaları üzerinde ve hekzan ekstraktlarının ise $C$. renale üzerinde etki gösterdiği görülmüştür.

\section{Mikrodilüsyon (MİK) Sonuçlart}

MíC sonuçları incelendiğinde ise farklı konsantrasyonlarda yapilan uygulamalarda bitki ekstraktlarının mikroorganizmlar üzerinde kayda değer bir etkiye sahip olduğu gözlemlenmiştir (Çizelge 2,3,4).

Çizelge 1. Echinops phaeocephalus türüne ait disk difüzyon testi sonuçları

\begin{tabular}{llll}
\hline Mikroorganizma & Methanol & Kloroform & Hekzan \\
\hline K. peumoniae & $8.31 \mathrm{~mm}$ & - & - \\
B. cereus & - & 12.90 & - \\
C. renale & $11.38 \mathrm{~mm}$ & 14.86 & 11.84 \\
M. luteus & 9.44 & & \\
\hline
\end{tabular}

Çizelge 2. Echinops phaeocephalus türünün kloroform ile elde edilen ekstraksiyonunun MİK sonuçları

\begin{tabular}{l|c|c|c|c|c|c|c|c}
\hline Kloroform & A & B & C & D & E & F & G & H \\
\cline { 2 - 8 } Konsanrtasyon (mg/ml) & 71.6 & 35.8 & 17.9 & 8.95 & 4.48 & 2.2 & 1.1 & Pozitif Kont. \\
\hline S. aereus & - & - & - & - & - & - & + & + \\
E. faecalis & - & - & - & - & - & + & + & + \\
P. fluorescens & - & - & - & - & + & + & + & + \\
S. epidermidis & - & - & - & - & - & + & + & + \\
M. luteus & - & - & - & - & + & + & + & + \\
L. monocytogenes & - & - & - & - & + & + & + & + \\
B. cereus & - & - & - & - & - & - & - & + \\
K. pneumonia & - & - & - & - & + & + & + & + \\
E. aerogenes & - & - & - & - & + & + & + & + \\
E. coli & - & - & - & + & + & + & + & + \\
B. subtilis & - & - & - & + & + & + & + & + \\
P. aeruginosa & - & - & - & - & + & + & + & + \\
C. renale & - & - & - & - & + & + & + & + \\
P. mirabilis & - & - & - & + & + & + & + & + \\
C. albicans & - & - & - & - & + & + & + & + \\
\hline
\end{tabular}

Çizelge 3. Echinops phaeocephalus türünün metanol ile elde edilen ekstraksiyonunun MİK sonuçları

\begin{tabular}{l|l|l|l|l|l|l|l|l}
\hline Metanol & \multicolumn{7}{l}{} \\
Mikroorganizmalar & A & B & C & D & E & F & G & H \\
\cline { 2 - 9 } Konsanrtasyon (mg/ml) & 100 & 50 & 25 & 12.5 & 6.25 & 3.13 & 1.56 & Pozitif Kont. \\
\hline S. aereus & - & + & + & + & + & + & + & + \\
E. faecalis & - & + & + & + & + & + & + & + \\
P. fluorescens & - & + & + & + & + & + & + & + \\
S. epidermidis & - & + & + & + & + & + & + & + \\
M. luteus & - & + & + & + & + & + & + & + \\
L. monocytogenes & - & + & + & + & + & + & + & + \\
B. cereus & - & + & + & + & + & + & + & + \\
K. pneumonia & - & - & + & + & + & + & + & + \\
E. aerogenes & - & - & + & + & + & + & + & + \\
E. coli & - & - & + & + & + & + & + & + \\
B. subtilis & - & + & + & + & + & + & + & + \\
P. aeruginosa & - & - & - & - & + & + & + & + \\
C. renale & - & - & - & - & + & + & + & + \\
P. mirabilis & - & - & - & - & + & + & + & + \\
C. albicans & - & - & - & - & + & + & + & + \\
\hline
\end{tabular}

Çizelge 4. Echinops phaeocephalus türünün hekzan ile elde edilen ekstraksiyonunun MİK sonuçları 


\begin{tabular}{l|l|l|l|l|l|l|l|l}
\hline Hekzan & \multicolumn{7}{l}{ G } \\
\hline Mikroorganizmalar & A & B & C & D & E & F & G & H \\
\cline { 2 - 9 } Konsanrtasyon (mg/ml) & 50 & 25 & 12.5 & 6.25 & 3.13 & 1.6 & 0.8 & Pozitif Kont. \\
\hline S. aereus & - & - & - & + & + & + & + & + \\
E. faecalis & - & - & - & + & + & + & + & + \\
P. fluorescens & - & - & + & + & + & + & + & + \\
S. epidermidis & - & - & + & + & + & + & + & + \\
M. luteus & - & - & + & + & + & + & + & + \\
L. monocytogenes & - & - & + & + & + & + & + & + \\
B. cereus & - & - & + & + & + & + & + & + \\
K. pneumonia & - & - & + & + & + & + & + & + \\
E. aerogenes & - & - & - & + & + & + & + & + \\
E. coli & - & - & - & + & + & + & + & + \\
B. subtilis & - & - & - & + & + & + & + & + \\
P. aeruginosa & - & - & - & + & + & + & + & + \\
C. renale & - & - & - & + & + & + & + & + \\
P. mirabilis & - & - & - & + & + & + & + & + \\
C. albicans & - & - & - & + & + & + & + & + \\
\hline
\end{tabular}

\section{Antioksidan Aktivite Belirleme Testleri}

\section{DPPH radikali süpürü̈cü aktivite tayini}

DPPH radikali doğal antioksidanların serbest radikal yakalama aktivitesini değerlendirmek için kullanılmaktadır. Çalışmada kullanılan bitkiye ait ekstraktların serbest radikal giderici etkileri DPPH radikali üzerinden tayin edildi. Standart madde olarak sentetik antioksidan olan BHT çözeltisi kullanılmıştır. Reaksiyon ortamındaki DPPH radikalinin \%50"sinin yok edilmesi için gereken etkili antioksidan konsantrasyonu $\mathrm{IC}_{50}$ değeri olarak tanımlanır ve düşük $\mathrm{IC}_{50}$ değeri yüksek radikal giderme aktivitesinin göstergesidir. $E$. phaeocephalus ekstraktlarının her biri için konsantrasyon $\%$ inhibisyon $\mathrm{IC}_{50}$ değerleri belirlendi ve elde edilen değerler aşağıdaki çizelgede verildi (Çizelge 5).

\section{Toplam Fenolik Bileşik Miktarı Tayini}

Toplam fenolik bileşik miktarı tayini için FolinCiocalteu reaktifi (FCR) kullanılmıştır. Ortamda fenolik maddelerin bulunması halinde FCR ilavesi ile 760 nm'de maksimum absorbans veren ürünler oluşmaktadır. 0.06 $\mathrm{mg} / \mathrm{ml}$ bitki örneği ile çalışılmış ve bu miktarın içerdiği fenolik madde miktarı fenolik bir madde olan gallik asit standart grafiği kullanılarak gallik asit eşdeğeri olarak belirlenmiștir. Fenolik içeriği en yüksek olan hekzan ile elde edilen ekstrakt iken, kloroform ile elde edilen bitki ekstraktında kayda değer bir fenolik içeriğe rastlanmamıştır (Çizelge 5).
Bitki ekstrelerinde, flavonoid madde miktarı bilinen bir flavonoid olan kuersetin standart grafiği kullanılarak, kuersetin eşdeğeri olarak belirlenmiştir. Flavanoid içeriği en yüksek olan metanol ile elde edilen ekstrakt iken, kloroform ve hekzan ile elde edilen bitki ekstraktında kayda değer bir flavanoid içeriğe rastlanmamıștır (Çizelge 5).

\section{SONUÇ}

$\mathrm{Bu}$ çalıșmada Bitlis ve Şırnak yöresinde yayılış gösteren $E$. phaeocephalus türünden elde edilen özütlerin antimikrobiyal ve antioksidan aktivitesi incelenmiştir. $\mathrm{Bu}$ kapsamda, üç farklı çözücü kullanılarak elde edilen ekstraktların antimikrobiyal etkileri MIK ve disk difüzyon metotları kullanılarak, antioksidan kapasiteleri ise toplam fenolik içeriğin belirlenmesi, toplam flavanoid içeriğin belirlenmesi ve DPPH radikal süpürücü aktivite tayini testleri yapılarak belirlenmiştir. Kullanılan çözücüler içerisinde en yüksek verim metanol ile yapılan ekstraksiyondan elde edilmiştir.

Mikrodilüsyon yöntemi sonucunda hekzan ve kloroform ekstraktlarının çalışılan 15 suş üzerinde de duyarlılık gösterdiği görülmüştür. Metanol ekstraktlarında ise en yüksek ancak en yüksek konsantrasyon seviyelerinde etki gözlenirken, sadece $P$. aeruginosa, $C$. renale, $P$. mirabilis ve $C$. albicans suşları üzerinde $6.25 \mathrm{mg} / \mathrm{ml}$ konsantrasyonlara kadar duyarlılık göstermiştir.

\section{Toplam Flavanoid İçeriğin Belirlenmesi}

Çizelge 5. E. phaeocephalus türünün antioksidan aktivite sonuçları

\begin{tabular}{|c|c|c|c|c|}
\hline & Metanol & Kloroform & Hekzan & BHT \\
\hline $\begin{array}{l}\text { Fenolik bileşik içeriği } \\
(\mathrm{mg} / \mathrm{gr})\end{array}$ & 2.76 & - & 15.9 & - \\
\hline $\begin{array}{l}\text { Flavanoid bileşik içeriği } \\
\text { (mg/gr) }\end{array}$ & 18.2 & - & - & - \\
\hline $\begin{array}{l}\text { DPPH süpürme aktivitesi \% } \\
50 \text { inhibisyon }(\mathrm{mg} / \mathrm{ml})\end{array}$ & 86.4 & 21.0 & 66.0 & 48.03 \\
\hline
\end{tabular}

DPPH radikali inhibisyon özellikleri; \% inhibisyon değerlerine göre incelendiğinde en yüksek inhibisyon değerine \% 86.4 inhibisyonla DPPH radikalini süpürücü etkisine metanol ekstraktında rastlanmıştır. En düşük 
inhibisyon değeri ise \% 21.0 inhibisyonla kloroform ekstraktında rastlanmıștır. E. phaeocephalus türünden elde edilen ekstraktların toplam fenolik içerikleri incelendiğinde en yüksek fenolik içerik miktarı hekzan ekstraktlarında görülürken, kloroform ekstraktlarında kayda değer miktarda fenolik içeriğe rastlanmamıştır. Ekstraktların toplam flavanoid içerikleri incelendiğinde ise methanol ekstraktlarında gallik asit eş değeri 18.2 $\mathrm{mg} / \mathrm{gr}$ olarak belirlenirken, hekzan ve kloroform ekstraktlarında kayda değer miktarda flavanoid bulunamamıştır.

Literatür çalışmaları incelendiğinde Echinops cinsine ait birçok farklı takson ile yapılan çalışmalarda, Echinops cinsine ait taksonların flavonoidler alkaloidler, saponinler, fitosteroller, polifenoller, carotenoidler, sesquterpenler, lactoneler, alkoller, lignanlar, asetilenik ve thiophen gibi bileşikler ve uçucu yağlar içerdiği belirtilmişlerdir. (Tadesse ve Abegaz, 1990; Sign ve Pandey, 1994; Hymete ve ark., 2005). Örneğin, Dawit ve Ahadu (1993), çalışmalarında Echinops cinsine ait bazı taksonların migren, kalp hastalıkları, bağırsak kurdu istilası, hemoroid ve diğer bazı hastalıkların tedavisinde kullanıldığı belirtilmişlerdir (Dawit\& Ahadu, 1993). Bir başka Echinops türü ile yapılan çalışmada ise, flavonoid bileşenlerinin gram-negatif organizmalara karşı güçlü inhibitör etkiye sahip olduğu ve bu tür organizmalar dışında bazı bulaşıcı hastalıklara yol açan bakteriler üzerinde de Echinops cinsi türlerinin kullanışlı olduğunu; ayrıca mollusca'lar üzerinde \%100 öldürücü etkiye sahip olduğu gözlemlemişlerdir.

Echinops phaeocephalus'un antimikrobiyal ve antioksidan aktivitesi ilk kez bu çalışma ile rapor edilmektedir. Araştırmamızda elde ettiğimiz sonuçları incelendiğinde, antimikrobiyal aktiviteye ve antioksidan değerlerin literatürde kabul edilen verilerle yakın değerler olduğunu görülmüştür. Hekzan ve kloroform ekstraktlarının çalışılan 15 suş üzerinde de duyarlılık gösterdiği görülmüştür. Literatür incelendiğinde, antimikrobiyal aktivite bakımından önemli değere sahip olan kantaron (Hypericum perforatum L.) bitkisinin etki göstermiş olduğu Escherichia coli, Klebsiella pneumonia, Bacillus cereus, Enterobacter aerogenes gibi birçok insana patojen bakteri üzerinde etkiye sahip olduğu gözlemlenmiştir (Akgöz, 2015). Antioksidan içerik bakımından da oldukça zengin olduğu bilenen standartlardan olan BHT ve bitkiler ile E. phaeocephalus türünün antioksidan etkisi karşılaştırıldığında çalışılan ekstraktların antioksidan etkisi olduğu sonucuna ulaşılmıştır. Örneğin DPPH süpürme aktivitesi tayininde standart antioksidan olarak kullanılan BHT ile özellikle de metanol ve hekzan ekstraktlarından elde edilen sonuçlar kıyaslandığında, E. phaeocephalus türünün önemli derecede antioksidan değeri olabileceği görülmüştür. Sonuç olarak, E. phaeocephalus ekstraktlarının bakterilerin antibiyotik dirençlerini kırmada kullanılabilecek potansiyelleri bulunduğu ve $E$. phaeocephalus türünün içerdiği biyoaktif moleküllerin belirlenmesi ve sonrasında da bu aktif bileşiklerin tıbbi olarak kullanılabilecek potansiyele sahip olabilecekleri bu çalışma ile vurgulanmıştır.

\section{TEŞEKKÜR}

$\mathrm{Bu}$ çalışma TÜBİTAK tarafindan TBAG $106 \mathrm{~T} 526$ nolu proje ile desteklenmiştir.

\section{KAYNAKLAR}

Akgöz Y 2015. The Effects of Hypericum (Hypericacea) Species on Microorganisms: A review. International Research Journal of Pharmacy, 6(7): 390-399.

Ameya G, Gure A, Dessalegn E 2016. Antimicrobial Activity of Echinops kebericho Against Human Pathogenic Bacteria and Fungi. African Journal of Traditional Complement and Alternative Medicines, 13(6): 199-203.

Chang CC, Yang MH, Wen HM, Chern JC 2002. Estimation of Total Flavonoid Content in Propolis by Two Complementary Colorimetric Methods. Journal of Food and Drug Analysis, 10(3): 178-182.

Dawit A, Ahadu A 1993. Medicinal Plantsand Enigmatic Health Practicesof Northern Ethiopia, Birhanena Selam, Addis Ababa, Ethopia 37-44.

Gamez-Meza N, Noriega-Rodriguez JA, Medina-Juarez LA, Ortega-Garcia J, Cazarez-Casanova R, AnguloGuerrero O 1999. Antioxidant activity in soybean oil of extracts from Thompson grape bagasse. Journal of the American Oil Chemists Society, 76: 1445-1447.

Gezer K, Duru ME, Kivrak I, Turkoglu A, Mercan N, Turkoglu H, Gulcan S 2006. Free-Radical Scavenging Capacity and Antimicrobial Activity of Wild Edible Mushroom From Turkey. African Journal of Biotechnology, 5(20): 1924-1928.

Güner A, Aslan S, Ekim T, Vural M, Babaç MT (edlr.) 2012. Türkiye Bitkileri Listesi (Damarlı Bitkiler). Nezehat Gökyiğit Botanik Bahçesi ve Flora Araştırmaları Derneği Yayını, İstanbul.

Haslam E 1996. Natural polyphenols (vegetable tannins) as drugs: possible modes of action. Journal of Natural Products, 59: 205-15.

Hymete A, Iversen TH, Rohloff J, Erko B 2005. Screening of Echinops ellenbeckii and Echinops longisetus for Biological Activities and Chemical Constituents. Phytomedicine 12: 675-679.

NCCLS (National Committee for Clinical Laboratory Standards) 1997. Performance Standards for Antimicrobial Disk Susceptibility Tests: Approved Standard Enclose -A 7. Wayne, PA,USA.

NCCLS (National Committee for Clinical Laboratory Standards) 1999. In Performance standards for antimicrobial susceptibility testing: 9th information supplement. Document M100-S9, Wayne, PA, USA.

Nissen N, Evans S 2012. Exploring the practice and use of Western herbal medicine: Perspectives from the social science literature. Journal of Herbal Medicine, 2: 6-15.

Singh RP, Pandey VB 1994. Further flavonoids of Echinops niveus. Fitoterapia, 65(4): 374.

Singleton VL, Rossi, JA 1985. Colorymetry of Total Phenolics with Phosphotungtenic Acid Reagent. American Journal of Enology and Viticulture, 16:144-58. 
Tadesse M, Abegaz B 1990. A review of the Genus Echinops (Composite, Craude) in Ethiopia with Notes on Phytogeography and Chemistry. Proceedings of the 12th Plenary Meeting of AETFAT, 4-10 September, Hamburg.
Toroğlu S, Keskin D, Vural C, 2012. Comparison of Antimicrobial Activity of Echinops viscosus subsp. bithynicus and E. microcephalus Leaves and Flowers Extracts from Turkey. International Journal of Agriculture and Biology, 14(4): 637-640. 